\title{
Direct Democracy Catalysed by Resident-to-Resident Online Deliberation
}

\author{
Rean van der Merwe and Anthony Meehan \\ Computing Department, The Open University, United Kingdom \\ r.vandermerwe@open.ac.uk, a.s.meehan@open.ac.uk
}

\begin{abstract}
In the context of local civic governance, much of the interest in eParticipation concerns the extent to which online media might overcome the limitations of geography and scale, and so allow local interests to be better represented in institutionally driven participatory processes at national or regional level. In contrast, this study investigates the online deliberations of a local, geographically bounded community in a series of mailing lists that had originated from their own initiative and self-organisation. The interactions we observe challenges assumptions of democratic deliberation as mainly policy debate between citizens and government, or of lobbying administrative government. It also proposes a broader conception of the role of online deliberation in local governance, where instrumental decision-making and developing consensus is frequently over privileged in research.
\end{abstract}

Keywords: e-Democracy, e-Participation, e-Governance, Neighbourhood democracy, Online Deliberation.

\section{Introduction}

Over the last decade, the growing availability of simple, free online communication tools such as bulletin boards, forums and mailing lists have seen these increasingly appropriated in local communities to support civic governance conversations between residents [1]. Bottom-up technology implementations have often been ad-hoc [2] without significant thought about design or the affordances [3] of the technology, and the assumption that the introduction of technology will likely strengthen local deliberation and coordination as long as it is sufficiently used. This paper presents a case study that investigates how the socio-technical environment [4] induced by the use of such online media mediates the governance practices of a small community, the residents of a semi-urban village in South Africa.

We approach this context of deliberation with the assumption that the dynamics of online interaction are likely to diverge from the state-centered interactions that are more commonly investigated in the research of e-democracy or e-participation [5-7]. Further, much of the related discourse implicitly focuses on how online interaction overcomes the limitations of geography and scale, and allows local interests to be represented in institutionally driven processes at national or regional level. This paper proposes the local context of a village or neighbourhood forum is conversely interesting exactly because the interaction of the online and offline is most visible there, and 
for the directness of engagement that very local issues afford - much as this raises new questions for research. In other words, the study follows the case selection logic proposed by Dahlberg [8] to extend the "first phase" of understanding of online deliberation - an opportunity to test established interpretations in a relatively underinvestigated context.

The local perspective questions assumptions of democratic deliberation as mainly policy debate between citizens and government, or of petitioning government locally. It also proposes a broader conception of the role of online deliberation in local governance, where instrumental decision-making [9] and developing consensus is frequently privileged in research. The dynamics we observe in the case study further raise a number of pertinent issues relevant to the design and implementation of systems to support such local governance conversations.

\section{Case Description}

The case study investigates the use of a range of online media in a small, geographically co-located community of approximately 1500 residents in on the outskirts of a large city in South Africa. The residents had voluntarily formed a "Residents and Ratepayers Association" (RRA) to attend to local governance and to represent the interests of the community to the city municipality which formally governs it. Because of geographic distances, low population density and limited human and financial resources, formal government have limited capacity at local level in South Africa [10].The RRA is accordingly formally recognised by the city municipality, and departments of the municipality interact with the RRA committee daily on matters ranging from infrastructure development to the delivery of basic and social services. In many cases, the RRA have assumed direct responsibility to co-ordinate and execute local governance actions.

In practice, the business of the RRA is conducted by a committee of five volunteers, elected at an annual general meeting (AGM). The committee has bi-monthly meetings that are open to all residents and ratepayers, though in reality the meetings are rarely attended by anyone but committee members. The RRA had experimented with the use of web-based tools, using volunteer technical assistance, to better co-ordinate their work, involve residents more actively and provide for a more communicative governing platform. Over a period of five years, the efforts included several iterations of a village website, an online forum, a map-based incident reporting tool and several email lists. The experimental, somewhat ad hoc approach meant that some of these tools had become redundant or had fallen into disuse when this study was conducted. Accordingly, we based our investigation on the main residents email list, as well as two topic-specific subsidiary lists, which together appeared to be the tools most prominently used to conduct governance. Though the online lists afforded users nothing more sophisticated than group email exchanges, they nonetheless appeared to afford complex deliberative interaction, and were broadly used. Residents could participate using whichever email client they already had 'at hand' [11], they were automatically forwarded conversations once they had subscribed to the list, and could reply directly from their email inbox. At the time of this study, the lists had 415 subscribers, estimated to represent approximately 
half of the households in the community. Of these, 81 subscribers had contributed messages in the preceding year ${ }^{1}$.

Our investigation focuses where off-line and on-line deliberation between citizens directly concerns questions of local governance, much as other conversations provided interpretive context. In this sense, the case study presents an example of "neighbourhood democracy" [7, 13]. However, it should be distinguished from studies of online neighbourhood democracy, or more broadly online deliberative governance, where the research focus is purely on the interaction of citizens with government, and where policy formulation in its various forms is both central object and output of communication. In this instance, the online discussion spaces were conceived, set up and are maintained entirely as a spontaneous volunteer effort by members of the community. Formal government, e.g. the city municipality, are neither the principal object of, nor significant participants in the conversations. Dialogue is between residents and largely concerns how they and their residents association might directly resolve local issues. Accordingly, residents understand the problems under discussion well, are often personally affected and appear highly motivated to participate in governance action. To the extent that they recognise the mandate or authority of external role players in issues, residents use the list to co-ordinate internally and then to provide locally consolidated input where they judge it will have appropriate effect.

\section{Approach}

Our goal was to use the case study as a form of "grounded account" [14], albeit informed by an acknowledged and developing theoretical framework, what Carrol and Swatman [15] refer to as 'structured case'. Epistemologically, the study takes an interpretive, constructivist approach. It considers governance in the first place a coconstructive [16] process - the shared defining of social reality and the possibilities for action therein, rather than a matter of primarily deciding between pre-existing options by a vote or poll [17]. The related technology is not treated deterministically, but its influence considered from the perspective that "sociotechnical developments do not determine political outcomes, but instead simply alter the matrix of opportunities and costs associated with political intermediation, mobilization, and the organization of politics" [18].

The research design incorporates several forms of triangulation [19] to improve the validity of interpretive claims: multiple data sources are used, constructs are developed correlating the outcomes of multiple methods of analysis, and the analysis relies on the direct interpretations of research participants as well as a group of external evaluators, as much as those of the principle researcher.

${ }^{1}$ While these numbers follow the expected pattern of diminishing participation at each level of engagement (relative to the overall population), the proportions are much higher than one might expect from examples in the literature 12. Preece, J., Abras, C., Maloney-Krichmar, D.: Designing and evaluating online communities: research speaks to emerging practice. International Journal of Web Based Communities 1 (2004) 2-18. To compare the online audience with that offline, the most recent AGM had 80 attendees, of whom 20 had an opportunity to make comment. 
In this paper we report on the second stage of the ongoing research project. An initial exploration of interactions on the community forum [20] employed course grained analysis of message content to establish an interpretive foundation for further work. The outcomes of this first stage of analysis were presented as a number of 'patterns of governance conversation', as well as preliminary observations on the dynamics contributing to each of these.

To investigate these preliminary findings in more detail, in particular to establish what interpretation community members themselves make of what had been observed, individuals were interviewed about a selection of thirty messages from the discussion archive. The material was theoretically sampled to be representative of the dynamics that had been proposed, while also giving a good cross section of authors and types of contribution. We interviewed 14 residents, as well as 4 'external' observers, chosen to triangulate our own interpretations with those of residents. The objective was to steer any further investigation and analysis through these grounded accounts, which used the sampled messages primarily as an aid to memory of specific events and the interactions related to them.

A triadic card sort [21] was used to structure the interviews, requiring participants to select 3 messages from the sample at random for each round of sorting and discussion. The 'triad sort' required that they identify a dimension that two of the messages shared, the third message representing an opposite or alternative. Participants were also requested to vocalise their thoughts as they worked. This produced two levels of data: by sorting and comparing messages participants produced 'personal constructs' [22] reflecting their interpretation of online interactions, and which could be used as the conceptual frame for further content analysis; at the same time, the in depth discussion of the material, as well as participants' rationale for sorting decisions, produced rich interpretive data.

\section{Interview Results and Content Analysis}

The interview process generated a set of 70 dimensions, too many to present in detail in this paper. However, as a first step of analysis, the constructs were grouped into four broad themes, which we do present below. Within these themes we present a number of 'key issues' - each informed by one or more of the constructs identified by participants in the card sort, relating these back to the governance interactions of the community. The themes are arranged here to reflect our own process of sense making and understanding, each theme developing on the basis of concepts presented in the previous themes.

\section{The (Local) Online Public Sphere}

This theme reflects on the affordances [3] of (geographically local) online interaction, compared to what may have been afforded otherwise. This presents the most literal interpretation of the 'matrix of opportunities and costs' [18] that we proposed to investigate of the new sociotechnical environment.

- Participants report a paradox: it is less intimidating to write a message on the forum than to confront a neighbour but, at the same time, almost everyone interviewed said 
they post less often than they would otherwise for fear of the response their message might evoke. A common response - "because I don't want to go there". This was particularly true of anything discursive or potentially contentious. In a local forum such as this, participating is everything but impersonal and anonymous. A comparison with contemporary field notes taken at the local ratepayers annual general meeting suggests the opposite in an 'offline' meeting - it is intimidating to speak up in front of a room full of people, but the stricter meeting protocol includes certain 'protections', if only a better sense of where opinions lie before speaking.

- Asynchronous conversation has its advantages and disadvantages. People are not excluded from conversation simply because they cannot be in a particular place at a certain time. On the other hand, the broken timeline can be very disruptive, with participants interjecting once a discussion had potentially moved on, and a number of conversations effectively mixed up in one channel. Where a face-to-face group discussion affords participants some sense of its progression, an indication of where opinions lie (e.g. by seeing nodding heads or agitated gestures), online a single dissenting voice can (for better or worse) derail a line of thinking because of the absence of these clues.

- Some of the residents we interviewed feel the online channel can be divisive creating 'sides', or even victims and perpetrators, where previously there had simply been a range of opinions. Related to this, participants express the concern that the 'open channel' reduces the possibility of a negotiated solution between directly affected parties, face-to-face. In stead, positions are established publically, broad judgements made, and often enough legal steps threatened (or taken) - damaging what many had perceived as a 'laissez faire' approach that the village is historically known for.

- Experience both during formal meetings and informal face-to-face conversations suggests that the online conversation often enough flows smoothly into offline interactions and back again. It is really not a separate 'space' as much as an extension of daily interaction. At the ratepayers AGM, issues that had emerged and been argued online are taken up and discussed exactly as any other. In turn, discussion at the AGM is smoothly continued online after the meeting. This is potentially a negative aspect for those who are not part of the online governance conversation though many of the online stalwarts are conversely not seen at the AGM. Their reasons vary from feeling co-opted by the meeting, to simply not being able to attend because of parental duties.

\section{Imagined Community}

The theme of 'imagined community' [23] departs from the notion that a sense of community, and the placement of oneself within that, is necessarily subjective and projected [24]. The forum, in turn, significantly impacts the sources an individual draws upon when constructing their sense of local community. This is particularly relevant if one approaches governance as a form of collective action - a coconstructive process of 'creating' meaning and therefore the potential for specific actions $[1,25]$, rather than a simple poll between pre-arranged options. 


\section{Key Issues Include}

- Participants are exposed to a potentially broader (less self selected) range of opinions and values on the list. Often enough residents interact with community members online that they have never met, or otherwise do not recognise from other contexts. In interviews, participants do however express unease over the projection of an 'online personality' versus that offline, the potential that the interaction online is one sided and participants quickly typecast after a 'hobby horse'.

- Participants identified how some shape roles for themselves online, in relation to their imagining of the community and their place therein. In some cases these roles extend their offline reality fairly directly, but not in all cases. Either way, some participants put a great deal of effort into 'presenting themselves', what Habermas [26] described as 'dramaturgical action.' It may be that the expectation of continued contact, and the likelihood of encountering other participants offline, is part motivation.

- The online conversation creates a shared frame of reference. During the card sort, participants would frequently immediately recognise a topic of conversation, identified consistently across interviews by some key phrase that had significance in the discussion. Often this would be the subject line of the email initiating a conversation. "Ah, the 'dogs out of control' story," someone would exclaim. This may otherwise not have been shared to the same extent. What these topics mean, or how they are interpreted, is however less shared than participants assumed. The divergent interpretations and perceptions of the value of different sorts of content (and styles of interaction) is a prominent feature during interviews. Participants also have divergent views on what 'belongs' on the forum.

- Might the forum place the ratepayers association, or particular role-players such as the forum moderator, more prominently in the residents' imagined community?

\section{Collective Action}

The previous section discusses aspects of each resident's imagined community, a potential driver and also modifier for collective action. This next section develops on this by focusing on some of the aspects of the collective action that were raised during interviews.

\section{Key Issues Include}

- During the first phase of the study we noted the organic, frequently ad hoc nature of local civic action, based on tacit agreement rather than formal decision-making process[20]. We reported evidence that the online interaction particularly facilitated the development of the shared frame of reference that made relatively informal governance possible - by supporting ongoing pluralist discussion, and particularly admitting expressive contributions which participants may have been too inhibited to make at a meeting. Yet, many of the interview participants communicated, to varying degrees, their disappointment with the online deliberation. For some, the discussions had become "more of the same", "rants" or "fear mongering." They felt that the deliberation derails all to often, leads nowhere, and may detract from people's willingness to eventually engage in practical action. 
- Many none the less agree that the forum has been very successful at mobilising the community and co-ordinating action where there is a clear course of action - to arrange community orientated events, co-ordinate the business of the local volunteer fire service, even to encourage local response to government requests for stakeholder input to regulations or policy. There are many who feel this is the forum's strongest use.

- The co-ordination of action was however not always as clear-cut or politically neutral as some would suggest. In many cases, what was presented as straightforward co-ordination did serve an additional agenda: the encouragement for residents to provide feedback would be accompanied by a 'briefing' that presented a very one sided view, and then go as far as providing 'template' objections, a range of arguments (from a particular point of view) for respondents to draw on. Though residents were presumed free to present alternative points of view on the forum, there is significant social pressure once consensus is so strongly implied. While this could be considered undemocratic on one hand, it does potentially serve to restore the balance of power where the 'opponent' - e.g. an external developer, or a government agency - is significantly better resourced than any single community member. In cases where the forum serves the interests of a group of participants over an individual however, a similar process may amount to 'bullying'.

\section{The Work of Governance}

One participant commented on the way that decisions are "usually" made at local level: a meeting is called, and those attending are assumed a quorum by virtue of their presence, the only ones with sufficient interest to share in the decision making process. While the online discussion alters this dynamic somewhat by allowing more open-ended participation, there are nonetheless new forms of potential exclusion as a result. Such issues of power and representation reflect an underlying tension between the 'work of governance', and the power associated with being in charge of local events. As another participant implied, there are many 'on the sidelines' who are quick to accuse the 'doers' of the abuse of power, though they themselves are unwilling to become involved beyond making comment.

\section{Key Issues Include}

- The residents association set up the forum as a tool to lower the cost of communication with residents, and, the moderator claims, to make their actions more transparent, given that residents did not attend monthly meetings of the committee. Yet the input on the forum remains informal, with almost deliberate steering away from giving the forum any more official status as deliberative tool. The chair claims discussion on the forum significantly influences their decisions - yet one might argue that the forum is potentially a strategy of containment [27], a way to give the community the impression of being informed and consulted - yet selectively so.

- The residents association sometimes deliberately conducts matters 'on the quiet' on the pretext that a storm of empty, habitual protest will quickly render any sort of action impossible. They argue that they are, after all, a democratically constituted body with clear duties that cannot allow constant interference with their efforts. Is there 'too much' democracy as a result of the online deliberation, allowing uncon- 
structive 'armchair dissent' to obstruct the work of governance? There is clearly a balance to be struck - the committee members are volunteers with little to gain by their local involvement, nor their role as go-between with government on matters of local service delivery.

- Some residents choose not to be subscribed to the forum at all, the 'cost' of being subjected to periodic conflict, or regular messages they have no immediate personal interest in, is too high. Those that are subscribed mentions 'noise' on the list (though definitions thereof diverge greatly) as one of their key complaints, and discuss various mechanisms which might be used to filter the stream of messages to a 'daily me'. Yet, the value of the list as community building and governance tool lies exactly in its reach and unfiltered nature, the fact that it is a genuinely shared channel. The list is potentially a 'public good', but one which requires work of its participants to maintain.

- Where there has been success, the list has been effective at sharing this and so developing both individual and collective political efficacy [28]. From the interviews, there is strong evidence that both the opportunity to provide input online, and the outcomes of some of the more visible community processes, has strengthened people's belief that 'something can be done' and that their input has been effectual. This is however not necessarily the outcome of online interaction - it clearly depends on how the list is used, and subsequently how both success and failure is communicated.

\section{Conclusion}

The work presented here is ongoing, and so any interpretations we make of the case must be provisional, much as we had not set out to propose predictive or causal hypotheses. The case does highlight how, much as the online public sphere might otherwise overcome issues of distance and scale, the geographically local context of resident-to-resident deliberation is shaped by particular dynamics and concerns exactly because conversations remain bound to place. It also shows that there are important processes of governance happening 'below' the level participative dialogue that would normally be considered in a top down process. Particularly relevant is the ability of a community or neighbourhood to self organise, to negotiate a dynamic and pluralist understanding of their governance reality, as well as to develop the efficacy to communicate this externally where required. This diverges from the conventional understanding of e-participation in terms of where the process initiative is placed, and what sort of process is potentially supported in the first place.

The detailed issues raised by participants in our study are not "new" of themselves - many ground insights that the discourse of online deliberation already has of the opportunities and challenges of web enabled communication recently e.g. summarized by Davies [29]. The responses do however propose shifts in emphasis, and invite fresh evaluation of the potential impacts in the local context. To summarise each of the themes we identified in turn:

- There are clearly advantages to communicating online, while at the same time the impersonal, asynchronous and above all uninhibited online interaction may at 
worst bully, divide and newly exclude [30, 31]. The potential for online interaction to be divisive, or otherwise destructive was the most broadly voiced concern of study participants, particularly salient in a context that implies continued face to face association, and where online dissent spills over very directly and unavoidably into daily life.

- To the extent that governance is a co-constructive process, the (local) online space provides access to a broader range of opinions [32], but also potentially affords relatively one-sided interaction within which this understanding must be constructed. While residents as a result likely had a broader view of the community than they may have otherwise had, active participants in the forum were typecast in a way that framed, sometimes for the worst, their potential contribution to future processes offline.

- Online tools removed some of the 'costs' associated with collective action, but introduced new costs [33], which must be negotiated if the space is to provide a long term 'public good'. For residents who did not previously participate in governance, joining the list simply resulted in an unanticipated rise in the cost that association had for them. Nonetheless, given the potential direct impact of the deliberation on their lives, relatively few chose to unsubscribe or avoid the list. Accordingly, almost all respondents had suggestions how this cost might be reduced by stronger moderation and filtering - particularly of more contentious issues.

- Much as the tools might be used to make governance transparent, they can be used as a strategy of containment, a diversion. To complicate the matter, there appear to be 'armchair critics' within the community who would use this argument unreasonably to subvert those willing to become involved in the thankless work of local governance. The RRA found themselves engaged on issues that were previously considered matter of course - greatly increasing their workload rather than reducing it, and potentially driving contentious issues 'under the radar' for fear of rendering their (volunteer) task impossible.

This is not to say these issues are intractable, but that there are balances to be struck, and that local online processes require careful facilitation, ideally informed by clearer understanding of the particular dynamics of geographically local deliberation than has often been the case. The dynamics within a community, and the interactions of its residents, are complex and a poorly managed attempt to reinvigorate local governance process online is just as likely to damage as it is to make governance more democratic or transparent.

\section{References}

1. Castells, M.: Communication, Power and Counter-power in the Network Society. International Journal of Communication 1, 238-266 (2007)

2. Engeström, Y.: From communities of practice to mycorrhizae. In: Hughes, J., Jewson, N., Unwin, L. (eds.) Communities of Practice: Critical Perspectives. Routledge, London (2007) 
3. Wellman, B., Quan-Haase, A., Boase, J., Chen, W., Hampton, K., Dİaz, I., Miyata, K.: The Social Affordances of the Internet for Networked Individualism. Journal of ComputerMediated Communication 8 (2003)

4. Kling, R., McKim, G., King, A.: A Bit More to It: Scholarly Communication Forums as Socio-Technical Interaction Networks. Journal of the American Society for Information Science \& Technology 54, 47-67 (2003)

5. Bertucci, G.: United Nations e-Government Survey 2008: From e-Government to Connected Governance, United Nations, New York (2008)

6. Vedel, T.: The Idea of Electronic Democracy: Origins, Visions and Questions. Parliamenry Affairs 59, 226-235 (2006)

7. Leighninger, M.: The promise and challenge of Neighbourhood Democracy. Deliberative Democracy Consortium, 24 (2008)

8. Dahlberg, L.: Net-public sphere research: Beyond the "first phase". Javnost 11, 27-44 (2004)

9. Gutmann, A., Thompson, D.F.: Why deliberative democracy? Princeton University Press, Princeton (2004)

10. Wunsch, J.S.: Decentralization, Local Governance and The Democratic Transition in Southern Africa: A Comparative Analysis. African Studies Quarterly 2 (1998)

11. Wenger, E., White, N., Smith, J.D., Rowe, K.: Technology for communities. Communities 2, 1-15 (2005)

12. Preece, J., Abras, C., Maloney-Krichmar, D.: Designing and evaluating online communities: research speaks to emerging practice. International Journal of Web Based Communities 1, 2-18 (2004)

13. Barber, B.R.: Strong democracy: participatory politics for a new age. University of California Press, Berkeley (2003)

14. Stake, R.E.: The art of Case Study Research. Sage, London (1995)

15. Carroll, J.M., Swatman, P.A.: Structured-case: a methodological framework for building theory in information systems research. Eur. J. Inf. Syst. 9, 235-242 (2000)

16. Hauser, G.A.: Vernacular Dialogue and the Rhetoricality of Public Opinion. Communication Monographs 65, 83 (1998)

17. Cohen, J., Sabel, C.: Directly Deliberative Polyarchy. European Law Journal 3, 313-340 (1997)

18. Bimber, B.A.: Information and American democracy: technology in the evolution of political. Cambridge University Press, Cambridge (2003)

19. Mingers, J.: Combining IS research methods: towards a pluralist methodology. Information Systems Research 12, 240-259 (2001)

20. Van Der Merwe, R., Meehan, A.: Direct deliberative local governance using online media? consensual problem solving or a recalcitrant pluralism?: From e-Participation to Online Deliberation. In: Proceedings of the Fourth International Conference on Online Deliberation, OD 2010, June 30-July 2, p. 13. University of Leeds, Leeds (2010)

21. Rugg, G., McGeorge, P.: The sorting techniques: a tutorial paper on card sorts, picture sorts and item sorts. Expert Systems 14, 80-93 (1997)

22. Kelly, G.A.: A brief introduction to personal construct theory. In: Perspectives in Personal Construct Theory, pp. 1-29. Academic Press, London (1970)

23. Anderson, B.R.: Imagined communities: reflections on the origin and spread of nationalism, Verso (1991)

24. Fayard, A.-L., DeSanctis, G.: Enacting language games: the development of a sense of, "we-ness" in online forums. Information Systems Journal 20, 383-416 (2009) 
25. Willcocks, L.P.: Foucault, Power/Knowledge and Information Systems: reconstructing the present. In: Mingers, J., Willcocks, L.P. (eds.) Social Theory and Philosophy for Information Systems, pp. 238-296. Wiley, Chichester (2004)

26. Klein, H.K., Huynh, Q.H.: The critical social theory of Jürgen Habermas and its implications for IS research. In: Mingers, J., Willcocks, L.P. (eds.) Social Theory and Philosophy for Information Systems, pp. 157-237. Wiley, Chichester (2004)

27. Isin, E., Wood, P.: Technological Citizenship. Citizenship and Identity, pp. 105-113. Sage, London (1999)

28. Anderson, M.R.: Community Psychology, Political Efficacy, and Trust. Political Psychology 31 (2010)

29. Davies, T.: The Blossoming Field of Online Deliberation. In: Davies, T.R., Peña Gangadharan, S. (eds.) Online Deliberation Design Research and Practice, pp. 1-20. CSLI Publications (2009)

30. Price, V.: Citizens Deliberating Online: Theory and Some Evidence. In: Davies, T., Gangadharan, S.P. (eds.) Online Deliberation: Design, Research, and Practice, pp. 37-58. CSLI Publications (2009)

31. Sunstein, C.R.: The Law of Group Polarisation. John M. Olin Law \& Economics Working Paper No. 91, p. 38. University of Chicago Law School (1999)

32. Lev-on, A., Manin, B.: Happy Accidents: Deliberation and Online Exposure to Opposing Views. In: Davies, T.R., Peña Gangadharan, S. (eds.) Online Deliberation Design Research and Practice, pp. 105-122. CSLI Publications (2009)

33. Cordella, A.: Transaction costs and information systems: does IT add up? Journal of Information Technology, 195-202 (2006) 